\section{Commentary: Frozen elephant trunk for acute dissection: Ready for prime time?}

\author{
Elizabeth H. Stephens, MD, PhD, and \\ Alberto Pochettino, MD
}

The frozen elephant trunk (FET) was introduced as the marriage of the established open anatomic arch replacement with the emerging technology of endovascular repair of the distal arch and descending thoracic aorta. ${ }^{1}$ Such marriage carries with it the advantages and disadvantages of each technology. A meta-analysis by Preventza and colleagues $^{2}$ summarizes the reported outcomes of FET, with a mortality of $8.8 \%$, a stroke rate of $7.6 \%$, and a spinal cord injury of $4.7 \%$, compared with available reports of conventional elephant trunk showing a $14.5 \%$ mortality, a $9.7 \%$ stroke rate, and a $2.6 \%$ risk of spinal cord injury. ${ }^{3}$ Thus, it suggests that FET has decreased the risk of mortality, trading it for an increased the risk of spinal cord injury. Unfortunately, the patients undergoing standard elephant trunk in the reviewed studies were not often directly comparable to those undergoing FET, with some of the differences possibly due to the nature of the disease rather than the surgical technique. Additional studies have delineated specific risk factors for spinal cord injury, such as length of the stent $15 \mathrm{~cm}$ or greater. ${ }^{2}$ Furthermore, because all endovascular techniques are prone to require reintervention, the FET has demonstrated to be no exception, with a reported risk of $49 \%$ at 2 years, most of which are secondary to endoleaks and distal stent graft-induced new tears and entry. ${ }^{4}$ As the FET has gained popularity, it has been suggested as the treatment of choice of acute DeBakey 1 dissections, which is the hypothesis of the review by Iino and colleagues. ${ }^{5}$

From the Department of Cardiovascular Surgery, Mayo Clinic, Rochester, Minn. Disclosures: The authors reported no conflicts of interest.

The Journal policy requires editors and reviewers to disclose conflicts of interest and to decline handling or reviewing manuscripts for which they may have a conflict of interest. The editors and reviewers of this article have no conflicts of interest.

Received for publication Dec 3, 2020; revisions received Dec 3, 2020; accepted for publication Dec 4, 2020; available ahead of print Dec 19, 2020.

Address for reprints: Elizabeth H. Stephens, MD, PhD, Department of Cardiovascular Surgery, Mayo Clinic, 200 1st St SW, Rochester, MN 55905 (E-mail: Stephens. Elizabeth@mayo.edu).

J Thorac Cardiovasc Surg 2022;164:1410-1

$0022-5223 / \$ 36.00$

Copyright (c) 2020 by The American Association for Thoracic Surgery

https://doi.org/10.1016/j.jtcvs.2020.12.038

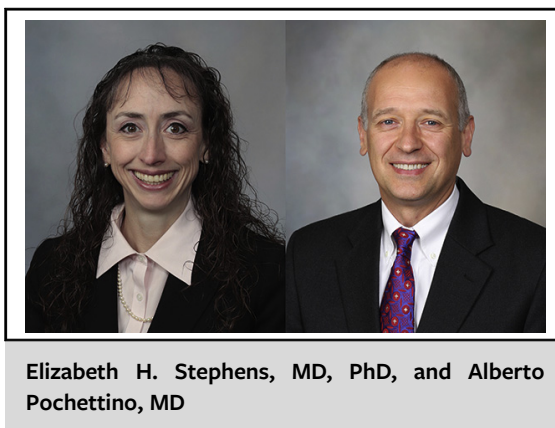

CENTRAL MESSAGE

As management of acute

dissection continues to improve, emphasis has been placed on treating the arch, including using a frozen elephant trunk. However, the optimal treatment remains undetermined.

In the study by Iino and colleagues, ${ }^{5} 50$ consecutive patients underwent total arch replacement with FET in zone 1 and 2 for acute DeBakey 1 aortic dissection using J Graft FROZENIX and Gelweave Lupiae graft (Vascutek Terumo Inc, Glasgow, Scotland). Their technique, following many other reports on performance of total arch replacement, ${ }^{6}$ moves the distal arch anastomosis more proximally. It also uses a rather complex setup for selective antegrade perfusion. The reported operative mortality was $4 \%$, permanent neurologic injury was $14 \%$, and spinal cord ischemia was $0 \%$. We congratulate them on their extremely low mortality, yet are concerned about a worrisome $14 \%$ permanent neurologic injury rate, despite their described "complete" selective antegrade perfusion approach. At a median of 21 months of follow-up, only 1 patient required reintervention at 4 months for progressive distal descending thoracic aortic dilation and 1 patient required reoperation for a proximal pseudoaneurysm. The authors performed a comparison of the FET group with a historical cohort of 26 patients who underwent total arch replacement without FET and found the mortality to be quantitatively lower in the FET group (4\% vs $15 \%)$ but was not statistically significant $(P=.331)$ because of small sample size. We think any historical control is intrinsically flawed by the many variables not controlled for, such as location of distal arch 
anastomosis, time delay from acute presentation to surgical intervention, degree of hypothermia, and specific cerebral perfusion strategy.

The question that remains unanswered by this report is whether FET is superior to hemiarch or even a "stented" hemiarch reconstruction for treatment of acute DeBakey 1 dissection. ${ }^{7}$ They did not perform such concurrent comparison. Following their lead, we also believe that a surgeon with experience in arch surgery should proceed with a FET when faced with an acute dissection. However, we believe just as strongly that a surgeon without sufficient arch reconstruction experience should not pick an acute dissection to perform a FET and should instead perform a standard hemiarch or at most a "stented" hemiarch reconstruction. Their report mentions that only 3 surgeons performed all 50 FET reconstructions, which is likely as important to their outstanding results as any other specific detail in their technique.

\section{References}

1. Kato M, Ohnishi K, Kaneko M, Ueda T, Kishi D, Mizushima T, et al. New graftimplanting method for thoracic aortic aneurysm or dissection with a stented graft. Circulation. 1996;94(9 Suppl):II188-93.

2. Preventza O, Liao JL, Olive JK, Simpson K, Critsinelis AC, Price MD, et al. Neurologic complications after the frozen elephant trunk procedure: a meta-analysis of more than 3000 patients. J Thorac Cardiovasc Surg. 2020;160: 20-33.e24.

3. Hanif H, Dubois L, Ouzounian M, Peterson MD, El-Hamamsy I, Dagenais F, et al Canadian Thoracic Aortic Collaborative I. Aortic arch reconstructive surgery with conventional techniques vs frozen elephant trunk: a systematic review and metaanalysis. Can J Cardiol. 2018;34:262-73.

4. Kreibich M, Berger T, Rylski B, Chen Z, Beyersdorf F, Siepe M, et al. Aortic reinterventions after the frozen elephant trunk procedure. J Thorac Cardiovasc Surg. 2020;159:392-9.e391.

5. Iino K, Takago S, Saito N, Ueda H, Yamamoto Y, Kato H, et al. Total arch replacement and frozen elephant trunk for acute type A dissection. J Thorac Cardiovasc Surg. 2022;164:1400-9.e3.

6. Yamamoto H, Kadohama T, Yamaura G, Tanaka F, Takagi D, Kiryu K, et al. Tota arch repair with frozen elephant trunk using the "zone 0 arch repair" strategy for type A acute aortic dissection. J Thorac Cardiovasc Surg. 2019 [In press].

7. Desai ND, Pochettino A. Distal aortic remodeling using endovascular repair in acute DeBakey I aortic dissection. Semin Thorac Cardiovasc Surg. 2009;21: 387-92. 